\title{
Dicotomias fiscais e distributivas dos ciclos político-orçamentários: análise da reserva de contingência nos municípios brasileiros
}

\section{Lucas Costa Souza}

Universidade de São Paulo (USP), São Paulo - SP, Brasil

\section{Ricardo Rocha de Azevedo}

Universidade Federal de Uberlândia (UFU), Uberlândia - MG, Brasil

\section{Jaime Crozatti}

Universidade de São Paulo (USP), São Paulo - SP, Brasil

O presente estudo objetivou verificar o nível de adequação da reserva de contingência no orçamento dos municípios brasileiros, partindo da hipótese de que, além do uso fiscal, ocorre uso político e distributivo de tal mecanismo no processo orçamentário. A teoria dos ciclos político-orçamentários, em conjunto com a literatura de gestão das finanças públicas, possibilitou o desenvolvimento do tema no contexto das dicotomias entre reequilíbrio fiscal e oportunismo político no orçamento público. Foram coletados dados do Sistema de Informações Contábeis e Fiscais do Setor Público Brasileiro para o período de 2015 a 2019. Realizou-se análise das estatísticas descritivas, adotandose o framework Pefa do Banco Mundial, e testes de diferenças de médias (teste $t$ de Student) das taxas da reserva de contingência. As análises evidenciaram uso adequado do mecanismo por parte dos municípios com resultado fiscal positivo. Por outro lado, os testes também permitiram sustentar uso político e oportunista da reserva frente ao cenário eleitoral. Verificou-se que os municípios deficitários têm postura incremental nos ciclos político-orçamentários. Os resultados trazem ponderações sobre as métricas do Banco Mundial e, sobretudo, implicações para a literatura de finanças públicas ao evidenciar que o uso oportunista da reserva de contingência pode dificultar o equilíbrio fiscal objetivado pela legislação e reduzir a credibilidade do orçamento. Espera-se que as descobertas impliquem em estudos futuros sobre especificações das bases de cálculo a serem consideradas para a reserva de contingência e para dispositivos orçamentários semelhantes.

Palavras-chave: dicotomias do orçamento público, credibilidade da reserva de contingência, ciclos político-orçamentários nas finanças públicas 


\section{Dicotomías fiscales y distributivas de los ciclos político-presupuestarios: análisis de la reserva de contingencia en los municipios brasileños}

El presente estudio tuvo como objetivo verificar el nivel de adecuación de la reserva para contingencias en el presupuesto de los municipios brasileños, con base en la hipótesis de que, además del uso fiscal, hay uso político y distributivo de este mecanismo en el proceso presupuestario. La teoría de los ciclos político-presupuestarios junto con la literatura sobre gestión de las finanzas públicas permitió desarrollar el tema en el contexto de las dicotomías entre reequilibrio fiscal y oportunismo político en el presupuesto público. Se recopilaron datos del Sistema de Información Fiscal y Contable del Sector Público de Brasil para el período de 2015 a 2019. Se analizaron estadísticas descriptivas utilizando el marco PEFA del Banco Mundial y pruebas de diferencias de medias (prueba t de Student) de las tasas de reserva para contingencias que mostraron un adecuado uso del mecanismo por parte de los municipios con resultados fiscales positivos. Por otro lado, las pruebas también permitieron sostener el uso político oportunista de la reserva, tomando en cuenta el escenario electoral. Se encontró que los municipios deficientes tienen una postura incremental en los ciclos político-presupuestarios. Los resultados aportan ponderaciones a las métricas del Banco Mundial e implicaciones para la literatura sobre finanzas públicas al mostrar que el uso político oportunista de la reserva para contingencias puede obstaculizar el equilibrio fiscal objetivado por la legislación y reducir la credibilidad del presupuesto. Se espera que los hallazgos impliquen estudios futuros sobre las especificaciones de las bases de cálculo a considerar para la reserva para contingencias y para otro tipo de provisiones presupuestarias.

Palabras clave: dicotomías del presupuesto público, credibilidad de la reserva para contingencias, ciclos político-presupuestarios en las finanzas públicas

\section{Fiscal and distributive dichotomies of political-budget cycles: analysis of the contingency reserve in Brazilian municipalities}

The present study aimed to verify the level of adequacy of the contingency reserve in the budget of Brazilian municipalities, based on the hypothesis that, in addition to fiscal use, there is political and distributive use of this mechanism in the budget process. The theory of political-budget cycles together with the literature on public finance management made it possible to develop the theme in the context of the dichotomies between fiscal rebalancing and political opportunism in the public budget. Data from the Brazilian Public Sector Accounting and Tax Information System were collected for the period from 2015 to 2019. Descriptive statistics were analyzed using the World Bank's PEFA framework, and tests of mean differences ( $t$ test of Student) of the contingency reserve rates that showed adequate use of the mechanism by the municipalities with positive fiscal results. On the other hand, the tests also allowed for opportunistic political use of the reserve, taking into account the electoral scenario. It was found that the deficient municipalities have an incremental stance in the political-budget cycles. The results bring weightings on World Bank metrics and implications for the public finance literature by showing that the opportunistic political use of the contingency reserve can hinder the fiscal balance objectified by the legislation and reduce the credibility of the budget. The findings are expected to imply future studies on the specifications of the calculation bases to be considered for the contingency reserve and for other types of budgetary provisions.

Keywords: dichotomies of the public budget, credibility of the contingency reserve, politicalbudget cycles in public finances 


\section{Introdução}

As crises financeiras têm influenciado de forma recorrente a gestão das políticas públicas e impactado as atividades de controle democrático, exigindo maior gerenciamento de riscos na administração pública. Tais medidas de austeridade, sugeridas por agências internacionais para gestão de recursos públicos, podem ser fonte de conflitos entre grupos de interesses políticos e servir ao oportunismo dos gestores públicos, tanto no âmbito das crises econômicas (PETERS, 2011) quanto em determinadas fases do ciclo político-orçamentário (Rogoff, 1990; MARCINIUK; BUgARIN, 2019; QUEIROZ et al., 2019; BARTOluzzio; Dos ANJos, 2020), na medida em que a desaceleração do crescimento mundial torna os orçamentos redistributivos e a disputa por recursos escassos tende a se acirrar (SCHICK, 1983). Com essa diversidade de posições em torno das finanças públicas, cabe considerar que, em perspectiva comparada, cada governo tem suas características as quais implicam em diferentes padrões de resposta às prescrições fiscais internacionais (Pollitt, 2003; Peters, 2011).

O orçamento público pode servir como mecanismo de gestão do equilíbrio fiscal e, ao mesmo tempo, ser resultado da negociação política do conflito por recursos escassos entre diversos grupos de interesses. Tal situação faz com que o orçamento público seja o centro de dimensões, muitas das vezes, antagônicas no cenário político e econômico. Essas dimensões são representativas da dicotomia entre gestão fiscal e padrões políticos, cuja discussão tem sido relevante para se compreender a gestão das crises e suas implicações no campo da administração pública (PETERS; PIERRE; RANDMA-LIIV, 2010).

Entre os aspectos das dicotomias do orçamento público, cabe destacar o uso da reserva de contingência, na medida em que as contingências despertam atenção por sua difícil operacionalização no processo orçamentário convencional (SCHICK, 2003). O tema encontra espaço no Brasil devido à tramitação de projetos de lei (PLP no 295/2016 na Câmara dos Deputados) que visam reestruturar as finanças públicas. A proposta não altera o caráter de gestão fiscal da reserva de contingência em comparação ao que já havia determinado a Lei Complementar no 101/2000 (Lei de Responsabilidade Fiscal - LRF). 
No cenário nacional, os dados divulgados pela Secretaria do Tesouro Nacional (2020) indicam que as prefeituras municipais costumam alocar baixos montantes em reservas de contingência. Esse cenário pode sugerir que as prefeituras não têm utilizado adequadamente o mecanismo de reserva como instrumento de prevenção de eventos imprevistos (contingências).

O projeto de lei orçamentária deveria comunicar de forma clara à sociedade quais são os gastos priorizados para o exercício subsequente e quais deixaram de ser alocados. Porém, uma das fragilidades recorrentemente apontadas quanto ao projeto de lei orçamentária é sua elevada imprecisão (REzende; CUNHA, 2013; AQUINo ; AzEvedo, 2015), impedindo que os objetivos planejados sejam alcançados e que a sociedade saiba o que está efetivamente sendo planejado. Nesse contexto, a reserva de contingência ocupa papel relevante, pois é um tipo especial de despesa no orçamento que não possui destinação específica, sendo utilizada como fonte de créditos adicionais para cobrir eventuais contingências. Assim, caso tenha valor elevado, pode funcionar como "cheque em branco" para os gestores, pois, de forma geral, as leis orçamentárias já autorizam o remanejamento dos valores da reserva de contingência para outros gastos.

O valor alocado na reserva de contingência tem sido apontado pelo Banco Mundial no projeto Pefa (Public Expenditure and Financial Accountability) como um dos elementos que devem ser acompanhados no orçamento, na medida em que pode representar imprecisão, caso tenha montante elevado (BANco MundIAL, 2018). O framework Pefa também é discutido pela literatura de Public Financial Management - PFM (ANDREWS, 2007; Aquino; AzEVEdo, 2015). Em conjunto com essa discussão, há necessidade de entender o comportamento da reserva de contingência em decorrência da possibilidade de ocorrerem manipulações políticas oportunistas, cuja discussão é iniciada com a teoria dos ciclos políticos (Downs, 1957; Nordhaus, 1975), na qual se baseia o modelo do Political Budget Cycle - PBC (Rogoff, 1990).

Em que pesem o fenômeno das dicotomias do processo orçamentário e as perspectivas político-orçamentárias até então apresentadas, este estudo tem como questão de pesquisa: qual o nível de adequação da reserva de contingência frente aos cenários eleitorais e fiscais nos orçamentos dos municípios brasileiros? 
Este artigo objetiva verificar a hipótese de que os gestores municipais não somente utilizam a reserva de contingência para gestão de riscos fiscais, como também a usam de forma oportunista (distributiva) no ciclo político-orçamentário. Para atingir o objetivo, foi realizada pesquisa quantitativa de caráter exploratório, buscando entender a adoção e o comportamento da reserva nos municípios.

O presente estudo tem relevância para o campo acadêmico da administração pública, na medida em que busca evidenciar uso político oportunista da reserva de contingência no contexto da dicotomia entre gestão do equilíbrio fiscal e conflito distributivo dos ciclos político-orçamentários. As evidências contribuem com a literatura de orçamento público ao indicar que os parâmetros da reserva de contingência afetam a credibilidade no orçamento anual brasileiro, haja vista que a possibilidade de uso políticodistributivo desse mecanismo se confronta com a gestão fiscal pretendida pela legislação de responsabilidade fiscal.

A seguir é apresentada a literatura que trata da reserva de contingência, incluindo suas dicotomias no processo orçamentário. Posteriormente, é apresentada a metodologia com os dados e técnicas de pesquisa. Por fim, são apresentadas as análises, os resultados e as conclusões da pesquisa.

\section{Referencial teórico}

\subsection{Reserva de contingência e sua adequação no orçamento público}

No âmbito nacional, a Lei Complementar no 101/2000 determina a fixação de dotação destinada à reserva de contingência no orçamento governamental. Seu artigo 5o estabelece que o projeto de lei orçamentária anual, elaborado de forma compatível com o Plano Plurianual e com a Lei de Diretrizes Orçamentárias, conterá reserva de contingência destinada ao atendimento de passivos contingentes e outros eventos fiscais imprevistos, cuja forma de utilização e montante, definido com base na receita corrente líquida, serão estabelecidos na Lei de Diretrizes Orçamentárias. Tais determinações, assim como os demais mecanismos da LRF, tiveram forte influência de instrumentos multilaterais como 
Budget Enforcement Act (EUA), Tratado de Maastricht (Europa) e Fiscal Responsability Act (Nova Zelândia) (ANTUNES, 2019).

Oliveira (2015) ressalta que a reserva de contingência não pode ser empenhada para qualquer despesa, devendo ser destinada para abertura de créditos suplementares e especiais somente depois de esgotadas as possibilidades de cancelamento de despesas correntes e de capital. A legislação possibilita a discricionariedade na gestão dessa reserva, sobretudo em tempos de crise fiscal, pela consignação de dotação para o atendimento de eventos futuros, certos ou incertos, e de riscos e eventos fiscais (Lei no 4.320, de 1964; LC no 101, de 2000). Tal dispositivo concede alto grau de discricionariedade ao Poder Executivo para optar pelas dotações nas quais serão aplicados os recursos da reserva de contingência. Assim, o governante está autorizado a utilizar, mediante decreto, os recursos da reserva de contingência para a abertura de créditos suplementares, reforçando as dotações das mais diversas ações públicas no orçamento anual.

Azevedo et al. (2019) indicam haver casos de municípios que propõem reserva de contingência com saldo insuficiente para suportar os riscos fiscais identificados na Lei de Diretrizes Orçamentárias, que a utilizaram como fonte de cobertura para a contingência. Com isso, a reserva representa mais um item que, na prática, é utilizado de forma cerimonial nos Anexos de Riscos Fiscais instituídos pela LRF.

A adequação das estimativas no orçamento público tem sido preocupação do Banco Mundial, pois a imprecisão pode afetar sua credibilidade. Uma das medidas de avaliação da credibilidade do orçamento público é o Pefa (Public Expenditure and Financial Accountability) (BANCo MUNDIAL, 2018), considerado como "uma iniciativa de um consórcio de agências, entre elas o Banco Mundial, que capta as diversas fases do ciclo orçamentário, desde a capacidade de previsão e execução do previsto" (AQUINO; AZEVEDo, 2015, p. 211).

Através do programa de avaliação de orçamentos Pefa, o Banco Mundial utiliza métricas para análise da credibilidade do orçamento, entre elas propõe a análise da reserva de contingência, cuja forma de utilização pode indicar autorização genérica dos gastos, na medida em que esse tipo de gasto autorizado no orçamento não possui destinação específica, atuando como se fosse um "cheque em branco" para os governos. O Banco 
Mundial reconhece que é prudente incluir um montante para permitir imprevistos na forma de uma reserva de contingência, porém, ela não deve ser tão grande a ponto de minar a credibilidade do orçamento (BANCO MUNDIAL, 2018).

No Pefa, a classificação da reserva de contingência é proposta em quatro grupos, atribuindo-Ihes notas de acordo com o montante alocado para a reserva, que pode indicar um orçamento genérico. $A$ avaliação atribui as seguintes notas: $(A)$ até $3 \%$ do orçamento; (B) entre $3 \%$ e $6 \%$ do orçamento; (C) entre $6 \%$ e $10 \%$ do orçamento; (D) acima de $10 \%$ (BANCO MUNDIAL, 2018).

Mesmo considerando as boas notas do Brasil no Pefa, é necessário olhar não apenas para os montantes per se, mas também para o destino e a aplicação dos recursos. Tais prescrições demandam cautela quando estudadas em perspectiva comparada no âmbito internacional (POLLITT, 2003).

A aplicação de modelos de avaliação no Brasil, a exemplo do Pefa, é conveniente para demonstrar aos usuários dos serviços públicos e às instâncias de controle e accountability os resultados da gestão governamental, mesmo que as ações incluídas nos instrumentos de planejamento não sejam de execução obrigatória (com exceção às emendas impositivas, criadas pelas Emendas Constitucionais no 86/2015 e no 100/2019), tendo em vista a característica meramente autorizativa do orçamento no Brasil (GIACOMONI, 2010).

O uso dos recursos alocados na reserva de contingência tem sido debatido pela literatura. Wehner (2006) afirma que alguns países usam reserva de contingência para cobrir necessidades imprevisíveis de gastos; no entanto, essa reserva deve ser claramente contabilizada e não deve ter tamanho excessivo. Apesar de ter pontos positivos, a lei que aprova a reserva de contingência, além de limitar o seu tamanho, precisa deixar claro qual é a natureza dos gastos a serem financiados pela reserva, as regras para acessar a reserva e a frequência dos relatórios para informar o legislador sobre os gastos realizados (ALLEN; HEMMING; POTTER, 2013). A reserva pode ser aprovada como uma proporção relacionada ao PIB do país, como ocorre na Hungria; em relação ao total de despesas aprovadas, que é o modelo mais comum e inclui o Brasil e o Japão; ou em relação às receitas, como em Honduras (CEBOTARI et al., 2009). 
Em todos os casos, a destinação das contingências precisa ser claramente indicada, mesmo se tratando de um crédito genérico. Do contrário, o mecanismo em questão pode acarretar mais uma forma de redução da credibilidade do orçamento anual.

\subsection{Aspectos inerentes à credibilidade do orçamento público}

A transparência e adequação quanto aos gastos efetivamente realizados com os recursos alocados na reserva de contingência são determinantes para os níveis de credibilidade do orçamento público. É preciso considerar que, além de representar crédito genérico aprovado na LOA, a execução de despesas com o uso da reserva de contingência funciona por meio de outros dispositivos de gerenciamento das mudanças que podem ocorrer no decorrer do exercício orçamentário. Essas situações estão previstas na Lei de Finanças Públicas (Lei no 4.320/64), sendo possível nesses casos fazer uso de dispositivos, tais como: alterações orçamentárias; créditos especiais, suplementares e extraordinários.

Anessi-Pessina, Sicilia e Steccolini (2012), por exemplo, apontam que as alterações orçamentárias, decorrentes de revisões dos valores planejados, representam mecanismos que dificultam a credibilidade do orçamento. Os casos de aumento dos valores orçamentários em relação aos valores iniciais são maiores do que os casos de redução, indicando subestimação orçamentária, pois os governantes favorecem uma previsão conservadora do orçamento inicial, subestimando as arrecadações, para se protegerem contra o risco de déficit de receita. Tal favorecimento à subestimação de receitas pelos governantes pode conter pontos positivos quanto à criação de uma margem de erro para angariar resultados orçamentários positivos, tornando menos provável que os gastos superem as arrecadações, haja vista ser necessário trabalhar com fatores imprevisíveis que podem ocorrer durante o período de execução orçamentária. Por outro lado, a subestimação das receitas pode dificultar o controle e a accountability dos recursos públicos.

Os créditos adicionais, a exemplo daqueles alocados com o uso da reserva de contingência, servem para corrigir situações não previstas na elaboração da proposta orçamentária. Por outro lado, tais mecanismos podem dificultar a identificação da realidade orçamentária caso não obedeçam aos pressupostos constitucionais, cuja utilização generalizada pode levar ao desvirtuamento do processo orçamentário (RocHA; MARCELINO; SANTANA, 2013). 
Aquino e Azevedo (2017) discutem a utilização do mecanismo de inscrição em restos a pagar, que representam o montante da dívida interna do ente governamental, ou seja, o quanto do orçamento comprometido (empenhado) foi processado (liquidado) ou não. A fraca regulação desse mecanismo em conjunto com o crescente endividamento público reduz drasticamente a credibilidade do orçamento como instrumento de gestão fiscal e de políticas públicas em todas as três esferas de governo, pois usam os restos a pagar como um mecanismo de orçamento paralelo para transportar créditos orçamentários de um exercício para outro.

Outras formas de revisão orçamentária podem ser incluídas entre as previsões legais que dificultam a avaliação do desempenho fiscal do ente público, uma vez que "transposição, remanejamento ou transferência de recursos não seriam outra coisa que retificações orçamentárias implementadas por meio dos créditos suplementares" (GIACOMONI, 2010, p. 313).

A imprecisão da previsão dos valores no orçamento público, que causa elevada proporção de alterações orçamentárias, não é uma particularidade do Brasil. AnessiPessina, Sicilia e Steccolini (2012) demonstraram que os governos locais na Itália realizam elevadas alterações no orçamento, geralmente motivadas por correção das falhas ocorridas na etapa de planejamento e ajustes derivados das alterações de políticas públicas.

O controle e a accountability dos recursos públicos podem ser afetados pela falta de realismo na gestão orçamentária que, por sua vez, se ampara na existência de mecanismos legais que dificultam a clara noção do resultado governamental. Por consequência, no Brasil fica evidenciado que "nos governos locais o Poder Executivo antecipa oportunidades e desafios na execução do orçamento, e prevê brechas nas estimativas" (AQUINO; AZEVEDo, 2015 , p. 210).

Apesar de o orçamento não permitir grandes manobras em relação à alocação de gastos entre as funções de governo por conta do seu comprometimento com aplicações vinculantes, como é o caso da saúde e educação, há considerável flexibilidade no remanejamento de verbas dentro das funções. O Legislativo tem como prática aprovar grandes percentuais de alterações orçamentárias que poderão ser feitas pelo Executivo no decorrer do exercício mediante decreto, mantidos os limites legais de aplicação de 
recursos (saúde e educação, por exemplo). Com isso, a reserva de contingência pode representar mais um mecanismo com margem distributiva que aumentaria a flexibilidade orçamentária. O principal relatório de gestão de riscos instituído pela LRF tem sido utilizado de forma cerimonial, apenas para cumprimento da legislação e não para uso efetivo na gestão pública (AZEVEDo et al., 2019). Nesse sentido, a reserva de contingência segue o mesmo panorama, pois representa um dos itens que podem compor o Anexo de Riscos Fiscais instituído pela LRF, como uma das fontes para as medidas eventualmente adotadas para os eventos listados no Anexo.

Por outro lado, a reserva de contingência possui objetivos que estão mais propensos à gestão dos riscos fiscais do orçamento. No entanto, falta na legislação nacional maior especificação das bases de cálculo, o que torna o mecanismo mais discricionário. A utilização da reserva com finalidades divergentes dos objetivos de gestão fiscal pode revelar inadequações e afetar a credibilidade das medidas fiscais demandadas pela legislação.

\subsection{Dicotomias do ciclo político-orçamentário e perspectivas teóricas}

As características da reserva de contingência, até então apresentadas, podem viabilizar tanto objetivos de controle fiscal quanto oportunismos políticos que são, muitas vezes, aspectos antagônicos no processo orçamentário. Ponderar essas duas dimensões é determinante para os níveis de controle e credibilidade do orçamento. Com isso, há dicotomias em torno da reserva de contingência que são sustentadas nesta pesquisa por duas perspectivas teóricas complementares sobre as características do uso desse mecanismo no orçamento público:

i.) Perspectivas de controle do ciclo Public Financial Management (PFM) - evidenciam a amplitude e a complexidade do ciclo de gestão das finanças públicas que equivale, no Brasil, ao ciclo de planejamento, aprovação, execução e controle orçamentário estabelecido pela legislação.

ii.) Perspectivas de oportunismo nos ciclos político-orçamentários - Political Budget Cycle $(P B C)$ - evidenciam as características inerentes ao uso do orçamento público de forma estratégica e eleitoral pelos governantes em determinadas etapas dos ciclos políticos. 
Esses dois pressupostos teóricos partem do princípio de que o orçamento é tradicionalmente apresentado como um conjunto de fenômenos decorrentes de negociações políticas, econômicas e sociais (WILDAVSKY, 1961), partindo do pressuposto de que as decisões governamentais tendem a ser incrementais (LINDBLOM, 1959). Por outro lado, as duas correntes (PFM e PBC) também são sustentadas pelo fato de que as crises mundiais passaram a despertar novas abordagens, as quais passaram a evidenciar que o orçamento se tornou redistributivo, exigindo novos olhares dos gestores sobre os gastos públicos em novos tempos ditados pela escassez de recursos (CAIDEN, 1982; SCHICK, 1983). Essas duas dimensões - aspecto incremental e redistributivo do orçamento - representam dicotomias que podem ser analisadas tanto no âmbito dos estudos do ciclo PFM quanto do PBC.

Quanto à primeira perspectiva teórica relacionada ao ciclo PFM, cabe considerar que a flexibilidade do orçamento está no centro do debate da literatura de finanças públicas, pois limita o controle fiscal dos gastos públicos e, ao mesmo tempo, representa elemento democrático de negociação dos conflitos sociais na fase de planejamento dos gastos. Sobre essa dicotomia, a literatura apresenta posições antagônicas sobre controle versus flexibilidade em relação à gestão dos gastos públicos. Robinson (2013) questiona se o orçamento público não deveria focar mais em resultados, ao mesmo tempo que permitiria uma maior flexibilidade aos gestores, desde que os objetivos sejam atendidos, o que implicaria na expressão: "deixem os gestores gerenciarem" (let the managers manage). Para isso, mecanismos de responsabilização deveriam ser adotados pelo eventual não atingimento das metas. Porém, o orçamento tem sido utilizado mais como um mecanismo de controle dos gastos, baseado em informações por tipos de despesas (inputs) e com baixa flexibilidade (SCHICK, 2014).

Há um trade-off sobre o tema identificado a partir de pesquisas que têm questionado se o orçamento deve ser rígido ou flexível para, justamente, suportar a imprevisibilidade que também é uma característica presente no setor público (FRANCESCO, 2016). Isso porque, de um lado, o orçamento deve comunicar previamente à sociedade o que o governo pretende fazer e, de outro, ele deve possuir mecanismos de ajustes para acomodar eventos urgentes e imprevistos que não podem suportar os lapsos temporais normalmente requeridos para alterações orçamentárias solicitadas junto à Casa Legislativa. 
No Brasil, a operacionalização da reserva de contingência se limita ao exercício orçamentário. O orçamento permeia praticamente todo o ciclo PFM e apresenta as políticas públicas que foram priorizadas, sendo orientado pela legislação e por interesses múltiplos, onde a informação financeira é primordial para registrar tais expectativas (WILDAVSKY, 1964; AQUinO; AZEVEdo, 2015).

Giacomoni (2010) ressalta a dinâmica do ciclo orçamentário, no qual o processo de planejamento e o orçamento devem ser considerados antes da etapa de avaliação e aferição dos resultados efetivados. De forma geral, fazem parte desse processo dinâmico de planejamento do orçamento: (i) elaboração e revisão do Plano Plurianual (PPA), que é confeccionado para o período de quatro anos de governo; (ii) elaboração e revisão de planos e programas nacionais, regionais e setoriais; (iii) elaboração e aprovação da Lei de Diretrizes Orçamentárias (LDO), que estabelece as prioridades e metas fiscais para o próximo exercício; (iv) elaboração da proposta orçamentária anual, que representa a previsão do que será executado no próximo exercício com base nas diretrizes orçamentárias; (v) discussão, votação e aprovação da Lei Orçamentária Anual (LOA); (vi) execução orçamentária propriamente dita; (vii) controle e avaliação da execução orçamentária.

Verifica-se que na LOA estão presentes os valores mais próximos de serem executados no decorrer do exercício financeiro. Logo, o controle do ciclo orçamentário ocorre principalmente durante a fase de execução anual, quando poderá ser verificado se o que foi estimado realmente ocorreu ou não, inclusive quanto aos valores registrados para a reserva de contingência.

A literatura traz ponderações em relação ao princípio da anualidade do orçamento, em grande medida devido aos saldos que se transferem para os próximos exercícios, o que limita o controle do que realmente ocorre no próprio ano (CAIDEN, 1982). Dessa forma, tal princípio também deve ser ponderado quanto ao tratamento dos riscos fiscais, cujos horizontes, na maioria das vezes, não se restringem ao curtíssimo prazo (ano orçamentário). Essa condição pode representar um incentivo para que os saldos da reserva de contingência sejam utilizados com finalidades adversas - por oportunismo político e distributivo - em detrimento dos objetivos fiscais da LRF, podendo afetar a credibilidade do orçamento público e até afetar o princípio da anualidade, dado que os créditos orçamentários aprovados no exercício podem estar sendo suportados por receitas do 
exercício seguinte, se estiverem em excesso, como discutido em Aquino e Azevedo (2017). Não por menos, os gastos orçamentários do ciclo PFM também têm sido discutidos sob o ponto de vista da Teoria dos Ciclos Políticos.

A Teoria dos Ciclos Políticos é a base da perspectiva do PBC, apresentado nesta pesquisa para entendimento do possível oportunismo em torno da reserva de contingência, que pode ir além da gestão de riscos fiscais no ciclo PFM. Os ciclos políticos têm sido amplamente debatidos. Marciniuk e Bugarin (2019) apontam que o tema tem ganhado atenção nos últimos anos, período em que diversos estudos buscaram justificar a relação entre processo eleitoral e gestão fiscal. Queiroz et al. (2019) indicam que a Teoria dos Ciclos Políticos se originou no intuito de explicar as decisões dos governantes no decorrer dos mandatos, destacando-se três abordagens evolutivas fundamentais até se chegar na perspectiva do PBC nas décadas de 1980 e 1990. Esse percurso inicia-se com os estudos de Downs (1957), passando pela formulação dos primeiros modelos empíricos com Nordhaus (1975), até apresentação por Rogoff (1990) do modelo conhecido por PBC (QUEIROz et al., 2019). A perspectiva de Rogoff - mais voltada para o estudo do impacto da manipulação política em variáveis fiscais e gastos orçamentários - representa uma das contribuições iniciais para a corrente de estudos denominada de "Modelos Racionais Oportunistas" (BARToluzzio; Dos Anjos, 2020).

A literatura internacional apresenta uma diversidade de estudos com base nos modelos de ciclos políticos, dentre os quais destacam-se os que utilizam o modelo racional "oportunista". Alesina e Roubini (1992), por exemplo, analisaram 18 países da OCDE buscando testar a implicação de vários modelos de ciclos políticos no comportamento do PIB, desemprego e inflação desses países, cujos resultados constataram que a inflação aumenta após as eleições em decorrência do oportunismo expansionista dos candidatos no período pré-eleitoral. Da mesma forma, outras implicações passaram a servir de suporte para o $P B C$, como é o caso dos efeitos dos resultados fiscais sobre a reeleição (BRENDER; DRAZEN, 2008) e das regras fiscais sobre o ciclo político (ROSE, 2006).

Um dos fatores que despertam resistências no processo orçamentário convencional é a constituição de reservas para contingências (SCHICK, 2003), o que também pode decorrer das implicações oportunistas discutidas pelas perspectivas dos PBC. A reserva de contingência é ilustrativa da dicotomia entre flexibilidade e controle orçamentário, pois 
a disputa política no âmbito da escassez de recursos faz com que pouca margem seja alocada para os objetivos de gestão fiscal da reserva de contingência, fazendo com que se tornem elementos da disputa de forma mais intensa em períodos pré-eleitorais. AnessiPessina, Sicilia e Steccolini (2012), ao analisarem os orçamentos dos municípios italianos, indicam a presença de influências que podem acarretar revisões do orçamento.

As orientações políticas envolvidas e as contingências são destacadas como as principais razões que levam ao incrementalismo na elaboração do orçamento inicial, na medida em que os municípios não consideram o cenário econômico e os riscos de forma "realista" no momento de planejar os gastos do ano subsequente (Aquino; AzEVEDo, 2015) e, assim, optam por apenas repetir os valores do passado com pequenos ajustes. Todavia, o orçamento deveria conciliar a realidade fiscal com as expectativas dos cidadãos (ANESSI-PESSINA; SICILIA; STECCOLINI, 2013).

A literatura nacional também tem se empenhado em entender os efeitos dos ciclos políticos enquanto fator relevante para análise da flexibilidade do planejamento orçamentário. Nesse sentido, verifica-se que as variáveis "ano eleitoral", "mudança de gestor público" e "mandato eleitoral" influenciam a abertura de créditos adicionais no orçamento (BALDISSERA et al., 2019). Com isso, há chances desses "oportunismos" políticos ocorrerem durante a elaboração das estimativas da reserva de contingência, tendo em vista as ações que os candidatos podem tomar para aumentar suas chances de reeleição.

Considerando-se a falta de estudos que busquem tratar diretamente da adequação do orçamento público com base na análise da reserva de contingência, estabeleceuse, a partir da literatura referenciada neste trabalho, que o comportamento do uso da reserva de contingência no orçamento pode envolver oportunismos no ciclo políticoorçamentário que dificultam a adoção de parâmetros contábeis para maior credibilidade do orçamento público. 


\section{Metodologia}

Tendo em vista os objetivos inicialmente descritos, este trabalho tem caráter exploratório e explicativo (MARTINS; THEÓPHILO, 2009), uma vez que apresenta evidências do uso fiscal e político da reserva de contingência na gestão orçamentária dos municípios brasileiros. Foram utilizadas estatísticas descritivas e testes de diferenças de médias para explorar e evidenciar a realidade na qual se insere o objeto da pesquisa.

Em princípio, buscou-se explorar e descrever os dados do orçamento anual dos municípios brasileiros para compará-los com as métricas avaliativas do Banco Mundial, no intuito de atingir o objetivo de pesquisa quanto à adequação do mecanismo da reserva de contingência no orçamento público. Nesse sentido, foram elaboradas estatísticas descritivas dos valores levantados. Entretanto, apenas a descrição estatística não se mostrou suficiente para testar a hipótese levantada quanto às estratégias políticas oportunistas de uso da reserva em cenários de conflito democrático e riscos fiscais. Assim, o framework Pefa - utilizado nas análises - não permitiu indicar as características políticas relacionadas ao uso dos mecanismos de gestão de riscos, que envolvem a complexidade dos níveis de interação dos atores (ANDREWs, 2007). Buscou-se, então, realizar testes de diferenças de médias no cenário dos resultados fiscais e eleitorais para captar o comportamento da reserva.

Os dados utilizados para as análises e testes foram coletados no sítio da Secretaria do Tesouro Nacional (STN, 2020), que oferece acesso aberto ao Sistema de Informações Contábeis e Fiscais do Setor Público Brasileiro (Siconfi). Do sistema, foi extraído o Relatório Resumido de Execução Orçamentária (RREO) dos municípios que disponibilizaram os dados ao Tesouro Nacional. Tal relatório contém o orçamento anual, no qual a pesquisa buscou verificar o nível de adequação da reserva de contingência.

A população da pesquisa representa os municípios brasileiros com os dados disponíveis (STN, 2020) para o período analisado, o que resultou em 4.282 em 2015, 4.079 em 2016, 4.562 em 2017, 5.457 em 2018 e 5.423 em 2019. Também foram coletados dados do sítio do Tribunal Superior Eleitoral (TSE, 2019) referentes às eleições municipais do ano de 2016. Tanto os dados orçamentários quanto eleitorais coletados foram tabulados e analisados com o software Excel $^{\circledR}$. 
Na coleta dos dados, foi delimitado o período de 2015 a 2019, que engloba partes dos ciclos políticos pertencentes às eleições de 2012 e 2016. Devido à indisponibilidade de todos os dados no Siconfi para o período de 2013 e 2014, não foi possível completar o ciclo político. Entretanto, no período utilizado estão inclusos dois fatores importantes para se entender o comportamento do objeto da pesquisa em distintos cenários do orçamento público: (i) a forte crise fiscal, que pode oportunizar diferentes reações dos administradores públicos (PETERS, 2011); (ii) as eleições municipais (em 2016), cujas estratégias e oportunismos políticos influenciam o orçamento público e seu resultado fiscal (BALdissera et al., 2019; Widyaningrum; Setiawan; Brahmana, 2019). Assim, o período é propício para entender as reações administrativas em relação à reserva de contingência em tempos de crise, bem como a liberalidade na utilização desse mecanismo orçamentário em períodos eleitorais.

O Quadro 1 demonstra os cálculos utilizados para a construção das variáveis de análise (taxas da reserva de contingência) que foram utilizadas para construção das estatísticas descritivas e aplicação dos testes de diferença de médias. As taxas representam as bases para as análises apresentadas na próxima seção desta pesquisa.

\section{Quadro 1 | Indicadores produzidos a partir dos dados coletados}

\begin{tabular}{|c|c|c|c|}
\hline Indicador & Formato & Descrição & $\begin{array}{l}\text { Rubricas orçamentárias e cálcu- } \\
\text { los utilizados }\end{array}$ \\
\hline \multirow{2}{*}{$\begin{array}{l}\text { Reserva de } \\
\text { contingência } \\
\text { estimada }\end{array}$} & \multirow[b]{2}{*}{ Таха } & \multirow{2}{*}{$\begin{array}{l}\text { Indica a relação entre o valor } \\
\text { previsto na rubrica da reserva } \\
\text { de contingência com o orça- } \\
\text { mento total originalmente } \\
\text { aprovado. }\end{array}$} & $T R E^{(1)}=V R F \div D T F$ \\
\hline & & & $\begin{array}{l}\text { Onde: } V R F=\text { Valor da Reserva de } \\
\text { Contingência Fixada; } D T F=\text { Valor } \\
\text { da Despesa Total Fixada. }\end{array}$ \\
\hline \multirow{2}{*}{$\begin{array}{l}\text { Reserva de } \\
\text { contingência } \\
\text { utilizada }\end{array}$} & \multirow[b]{2}{*}{ Taxa } & \multirow{2}{*}{$\begin{array}{l}\text { Indica a relação entre o valor } \\
\text { utilizado da reserva de con- } \\
\text { tingência com o orçamento } \\
\text { total originalmente aprovado. }\end{array}$} & $T R U^{(1)}=V R U^{(2)} \div D T F$ \\
\hline & & & $\begin{array}{l}\text { Onde: } V R U^{(2)}=\text { Valor da Reserva } \\
\text { de Contingência Utilizada; DTF = } \\
\text { Valor da Despesa Total Fixada. }\end{array}$ \\
\hline
\end{tabular}

Fonte: elaborado pelos autores.

Nota: (1) Taxa de Reserva Estimada (TRE) está ligada à previsão orçamentária (valores estimados) e Taxa de Reserva Utilizada (TRU) está liga à execução orçamentária (recursos efetivamente utilizados); (2) Valor da Reserva de Contingência Utilizada (VRU) representa a soma dos valores liquidados e, principalmente, dos valores de alterações que ocorreram na rubrica da reserva de contingência durante a execução do orçamento, pois tal reserva é mais utilizada a partir da suplementação em outras rubricas orçamentárias. 
Com as taxas representativas dos valores da reserva de contingência, foram elaboradas tabelas descritivas das medidas básicas de tendência central e dispersão (MARTINS; THEÓPHILO, 2009), de modo a analisar o comportamento das variáveis foco da pesquisa.

\section{Resultados e análises}

\subsection{Descrição das variáveis}

A primeira análise descritiva desta pesquisa apresenta a relação quantitativa das taxas da reserva de contingência estimadas e utilizadas (TRE e TRU) em comparação com a métrica do Banco Mundial (2018), conforme parâmetros Pefa (BANCo MUNDIAL, 2018). O framework Pefa tem alcance internacional enquanto ferramenta destinada a mensurar a qualidade do processo de gestão financeira em governos (ANDREWS, 2007), por esse motivo foi escolhido como parâmetro para as análises iniciais desta pesquisa em relação à adequação da reserva de contingência dos municípios brasileiros aos indicadores fiscais internacionais.

As faixas de percentuais da Tabela 1 foram estabelecidas englobando os cálculos do período de 2015 a 2019. A princípio, tais classificações demonstram adequação das estimativas. 
Tabela 1 | Descrição das taxas de reserva de contingência, com métricas do Banco Mundial (2018)

\begin{tabular}{ccccccccccc}
\hline \multirow{2}{*}{$\begin{array}{c}\text { Nota } \\
\text { Pefa }\end{array}$} & Classificação & \multicolumn{4}{c}{ Taxa da reserva estimada } & \multicolumn{3}{c}{ Taxa da reserva utilizada } \\
\cline { 3 - 8 } & $\mathbf{N}^{(1)}$ & Média & Mínimo & Máximo & $\mathbf{N}^{(1)}$ & Média_ Mínimo Máximo \\
\hline -- & Sem reserva & 1.046 & 0,0000 & 0,0000 & 0,0000 & 9.348 & 0,0000 & 0,0000 & 0,0000 \\
-- & Até 0,01\% & 243 & 0,0001 & 0,0000 & 0,0001 & 157 & 0,0000 & 0,0000 & 0,0001 \\
A & 0,01\% a 3\% & 20.187 & 0,0075 & 0,0001 & 0,0300 & 13.717 & 0,0080 & 0,0001 & 0,0300 \\
B & $3 \%$ a 6\% & 1.318 & 0,0414 & 0,0300 & 0,0599 & 501 & 0,0376 & 0,0300 & 0,0597 \\
C & $6 \%$ a 10\% & 640 & 0,0768 & 0,0600 & 0,0998 & 64 & 0,0790 & 0,0603 & 0,1000 \\
D & > de 10\% & 369 & 0,1290 & 0,1000 & 0,2811 & 16 & 0,1247 & 0,1000 & 0,1930
\end{tabular}

Fonte: elaborado pelos autores, com base nos valores do Siconfi (STN, 2020).

Nota: (1) "N" representa a quantidade de orçamentos dos municípios de acordo com as notas atribuídas em cada período: 2015 (4.282), 2016 (4.079), 2017 (4.562), 2018 (5.457) e 2019 (5.423) totalizando 23.803 observações nos quatro períodos; (2) 49 municípios apresentaram taxas negativas de reserva utilizada, decorrentes de alterações orçamentárias que aumentaram os valores previstos na rubrica sem ocorrer a efetiva utilização dos valores.

Quanto às taxas de reserva utilizadas, que representam a base de cálculo original do parâmetro proposto pela avaliação do projeto Pefa, foi evidenciado que 35\% dos municípios estimaram a reserva de contingência no orçamento inicial, mas apresentaramse na faixa dos municípios "sem reserva utilizada". Apesar dessa situação poder ser decorrente da não materialização dos riscos, as "sobras" de recursos no orçamento também não são desejáveis em tempos redistributivos. No contexto da avaliação do ciclo PFM, a constatação da Tabela 1 contribui para evidenciar que as estimativas aprovadas no orçamento anual podem não apresentar segurança razoável de que serão cumpridas no decorrer do exercício fiscal. Dessa forma, é necessário considerar que existem diversos processos de PFM não cobertos pela estrutura Pefa, em que pese a multiplicidade de atores com diferentes domínios e níveis de interação (ANDREWS, 2007).

A segurança de que as estimativas de contingências serão razoavelmente cumpridas representa um fator importante na multiplicidade de interações entre os atores que compõem o ciclo PFM. Nesse ponto, faz-se oportuna uma ressalva em relação às diferenças das informações orçamentárias e patrimoniais. Para os itens patrimoniais, a legislação nacional tem avançado em relação à mensuração dos passivos contingentes, em especial a NBC TSP 03 - Provisões, Passivos Contingentes e Ativos Contingentes (CFC, 
2016) -, possibilitando maior segurança quanto ao "impacto do passivo existente sobre os recursos futuros" (CRUVINEL; LIMA, 2011, p. 81).

Alguns países têm adotado o regime de competência também para o orçamento, que apresenta vantagens na identificação das contingências pagas no futuro e na melhora da accountability; mas, esses mesmos estudos também destacam algumas desvantagens como a excessiva rigidez, complexidade técnica e política para adoção desse tipo de orçamento (SCHICK, 2007; MONTEIRO; GoMES, 2013). No Brasil, a LRF e o Projeto de Lei no 295/2016 optaram por preservar o regime de caixa para as informações orçamentárias.

De um lado, entre os municípios analisados, 4\% não constituíram reserva de contingência no orçamento anual. Por outro lado, municipalidades chegaram a alocar $19 \%$ do orçamento total somente com o mecanismo da reserva de contingência. Apesar dessas distorções não apresentarem as características predominantes da população, causa surpresa terem sido aprovadas pelo Legislativo, pois a realidade fiscal de escassez de recursos torna o orçamento redistributivo (CAIDEN, 1982; SCHICK, 1983), não havendo grandes margens de manobra do Executivo junto ao Legislativo. Além disso, essas informações deveriam ser facilmente detectáveis pelo Legislativo no processo de aprovação do orçamento, o que pode ser mais uma evidência da baixa reflexividade e atuação das comissões de orçamento e finanças dos legislativos municipais (DomıNGos; AQUINo, 2019).

Em média, os municípios chegam ao final do exercício fiscal com sobras de $55 \%$ em dotações na rubrica de reserva de contingência, o que se torna preocupante no contexto da crise fiscal vivenciada no período dos dados analisados. Apesar da reserva ser destinada à gestão de riscos e não poder ser utilizada no decorrer do ano sem os devidos critérios, o alto percentual de sobras nesse tipo de dotação indica erros de projeções por parte dos gestores públicos. Dessa forma, vale destacar que os recursos previstos no orçamento e não utilizados no exercício fiscal também não acumulam para os exercícios seguintes devido ao princípio orçamentário da anualidade previsto no art. 2o da Lei no 4.320, de 1964. Esse trade-off entre critérios de uso e estimativas da reserva deve ser considerado em termos de análise do orçamento público, pois a reserva de contingência deve ser utilizada apenas para eventos contingentes, mantendo até o final do ano o recurso porventura não utilizado; mas não deve haver grandes sobras decorrentes de erros nas 
estimativas orçamentárias, pois é necessário considerar que os recursos são escassos e diversos serviços públicos necessitam de recursos para sua continuidade e para serem executados até o final do ano orçamentário.

Os resultados iniciais das análises descritivas com o framework Pefa demonstram seu baixo potencial em captar estratégias e oportunismos na utilização da reserva de contingência. Mesmo que as contingências fossem executadas de forma próxima ao estimado para ocorrer no exercício, não se teria a certeza de que o mecanismo seria utilizado para a gestão dos eventos fiscais imprevistos, conforme prevê a legislação. Nesse sentido, a literatura aponta que os instrumentos de gestão de riscos, em especial os Anexos de Riscos Fiscais que incluem as contingências, apresentam uso cerimonial (AZEVEDo et al., 2019).

Verifica-se que os atores políticos podem se utilizar de estratégias oportunistas em relação ao conflito distributivo do orçamento público, principalmente com objetivo de serem reeleitos (SAKURAI, 2009; NAKAgUMA; BENDER, 2010). Assim, torna-se relevante entender o comportamento das taxas médias de reserva de contingência em relação aos resultados fiscais e eleitorais alcançados pelos atores políticos no cenário da crise e das eleições municipais de 2016.

O resultado orçamentário é relevante no sentido de evidenciar a situação fiscal efetivamente executada (GIACOMONI, 2010), sendo possível identificar os resultados fiscais dos atores no ciclo PFM. Quanto ao resultado eleitoral, seu comportamento é relevante no sentido de captar as estratégias de reeleição dos governantes dentro do ciclo político e eleitoral (BALDISSERA et al., 2019).

A separação dos grupos em resultados fiscais e eleitorais foi realizada com uso das mesmas bases de dados utilizadas na construção da Tabela 1 e com os mesmos cálculos definidos no Quadro 1. A Tabela 2 apresenta as estatísticas descritivas (média, valor mínimo e valor máximo) das variáveis em análise utilizadas nos testes que serão apresentados na próxima subseção do artigo. 
Tabela 2 | Descrição das taxas de reserva de contingência, por grupos de resultados fiscais e eleitorais

\begin{tabular}{llllllll}
\hline & & \multicolumn{2}{c}{ Taxa da reserva estimada } & \multicolumn{2}{c}{ Taxa da reserva utilizada } \\
\cline { 3 - 8 } Resultado: & N & Média & Mínimo & Máximo & Média & Mínimo & Máximo \\
\hline 1. Orçamentário ${ }^{(1)}$ & & & & & & & \\
Superavitários & 15.784 & 0,0145 & 0,0000 & 0,2811 & 0,0058 & $-0,0602$ & 0,1930 \\
\hline Deficitários & 8.019 & 0,0092 & 0,0000 & 0,1605 & 0,0054 & $-0,0289$ & 0,1605
\end{tabular}

2. Eleitoral

\begin{tabular}{lccccccc} 
Reeleitos $^{(2)}$ & 5.852 & 0,0120 & 0,0000 & 0,2171 & 0,0053 & $-0,0071$ & 0,0910 \\
\hline $\begin{array}{l}\text { Não reeleitos e suces- } \\
\text { sores }^{(3)}\end{array}$ & 6.525 & 0,0131 & 0,0000 & 0,2811 & 0,0059 & $-0,0602$ & 0,1727
\end{tabular}

Fonte: elaborado pelos autores, com base nos valores do Siconfi (STN, 2020) e do TSE (2019).

Nota: (1) O cálculo do resultado orçamentário representa a diferença entre a receita total arrecadada e a despesa total empenhada; se for positivo, o município apresenta-se no grupo superavitário; se for negativo, apresenta-se no grupo deficitário; (2) Reeleitos representam o grupo dos candidatos que se reelegeram para o segundo mandato após o pleito eleitoral de 2016 (1.023 em 2015, 1.041 em 2016, 1.114 em 2017, 1.336 em 2018 e 1.338 em 2019); (3) Não reeleitos e sucessores representam o grupo de candidatos em primeiro mandato que não se reelegeram no pleito de 2016 (1.178 em $2015,1.060$ em 2016), mais os candidatos que se elegeram para o primeiro mandato no pleito eleitoral de 2016, sucessores dos não reeleitos (1.256 em 2017, 1.529 em 2018 e 1.502 em 2019). Cabe ainda destacar que nos dados do TSE referentes ao pleito eleitoral de 2016 foram identificados 2.926 ocupantes de cargos do Executivo municipal que foram candidatos à reeleição, dos quais somente 1.371 (47\%) foram reeleitos. Os dados da Tabela 2 englobam somente o resultado eleitoral para os candidatos dos municípios com dados orçamentários disponíveis na base do Siconfi, totalizando 12.377 observações nos cinco períodos. Nas próximas seções, os dados da Tabela 2 são explorados em maior profundidade.

\subsection{Testes e resultados}

A partir das taxas médias de reserva de contingência calculadas (Tabela 2), foram realizados testes de diferenças de médias (teste $t$ de Student) com o objetivo de verificar a hipótese de haver uso estratégico-oportunista em torno do mecanismo, em que pesem os cenários fiscais e eleitorais no orçamento dos municípios brasileiros. Os testes consistem em verificar se há diferença nas taxas médias da reserva de contingência em dois cenários distintos: quando comparados os dois grupos possíveis (superávit versus déficit) do resultado orçamentário e quando comparados os dois grupos (reeleitos versus não reeleitos com sucessores) do resultado eleitoral. Conforme demonstrado na Tabela 3, foi aplicado o teste t de Student, considerando-se um nível de significância de 95\% como forma de validar a análise do comportamento das variáveis com a diferença das médias (MARTINS; THEÓPHILO, 2009). 
Tabela 3 | Resultados dos testes de diferença de médias

\begin{tabular}{|c|c|c|c|c|}
\hline \multirow[t]{2}{*}{ Grupos comparados } & \multirow{2}{*}{$\begin{array}{l}\text { Variável de com- } \\
\text { paração - taxa da } \\
\text { reserva de contin- } \\
\text { gência }\end{array}$} & \multicolumn{2}{|c|}{ Média (Desvio-padrão) } & \multirow{2}{*}{$\begin{array}{l}\text { Significância do } \\
\text { Teste } t \text { de Stu- } \\
\text { dent ( } p \text {-value) }\end{array}$} \\
\hline & & $\begin{array}{l}\text { Municípios } \\
\text { com superávit }\end{array}$ & $\begin{array}{l}\text { Municípios } \\
\text { com déficit }\end{array}$ & \\
\hline \multirow{3}{*}{$\begin{array}{l}\text { Municípios com superá- } \\
\text { vit versus déficit (Resul- } \\
\text { tado orçamentário) }\end{array}$} & Taxa utilizada & $0,006(0,010)$ & $0,005(0,009)$ & 0,001 \\
\hline & Taxa estimada & $0,015(0,024)$ & $0,009(0,013)$ & 0,000 \\
\hline & & $\begin{array}{l}\text { Prefeitos } \\
\text { reeleitos }\end{array}$ & $\begin{array}{l}\text { Prefeitos não } \\
\text { reeleitos }\end{array}$ & \\
\hline \multirow{2}{*}{$\begin{array}{c}\text { Prefeitos reeleitos } \\
\text { versus não reeleitos e } \\
\text { sucessores (Resultado } \\
\text { eleitoral) }\end{array}$} & Taxa utilizada & $0,005(0,008)$ & $0,006(0,010)$ & 0,001 \\
\hline & Taxa estimada & $0,012(0,020)$ & $0,013(0,022)$ & 0,004 \\
\hline
\end{tabular}

Fonte: elaborado pelos autores.

Com a média e o desvio-padrão de cada variável e grupo de comparação (Tabela 3), verifica-se que a maior diferença entre as médias está na taxa estimada do comparativo envolvendo os grupos do resultado orçamentário. Apesar de menores, as demais comparações também apresentam diferença de médias ( $p$-value menor que $0,05)$. Considerando a significância estatística dos testes, foram elaborados gráficos comparativos (Figuras 1 e 2) sobre o comportamento das variáveis em cada um dos cinco períodos, de 2015 a 2019, visando evidenciar as diferenças observadas em relação ao comportamento do uso fiscal e estratégico-oportunista da reserva de contingências no processo orçamentário.

A Figura 1 demonstra que os municípios com superávit orçamentário apresentam maior aderência à gestão de riscos fiscais demandada pela legislação, na medida em que o comportamento das taxas não é linear e expressa certa estratégia de aumentos e diminuições nas estimativas em linha com o cenário econômico nacional e com a própria situação de arrecadação dos municípios no período. Já os municípios deficitários possuem comportamento evidentemente incremental, na medida em que as variações nas taxas são pequenos acréscimos marginais em relação ao ano anterior, sem expressar a realidade econômica e fiscal. 
Figura 1 | Diferenças das médias da reserva de contingência entre os grupos do resultado orçamentário

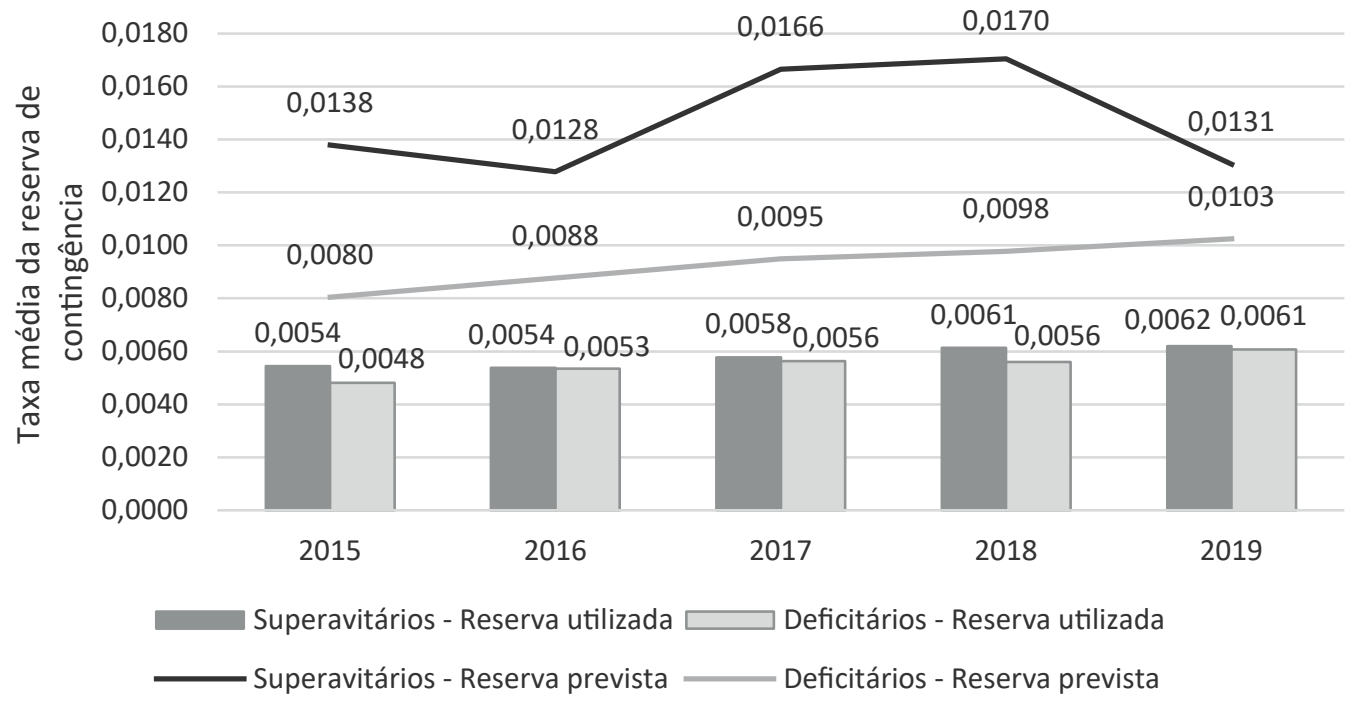

Fonte: elaborado pelos autores.

Nota: (1) Reserva prevista representa as taxas médias de utilização (recursos orçamentários executados) da reserva de contingência para cada um dos grupos do resultado orçamentário; (2) Reserva utilizada representa as taxas médias estimadas (valores do orçamento inicialmente proposto) da reserva de contingência para cada um dos grupos do resultado orçamentário.

O cenário apresentado na Figura 1 permite corroborar a avaliação Pefa quanto à adequação dos montantes das contingências nos municípios brasileiros. Apesar de haver uma "ascensão" das taxas de reserva entre o ano eleitoral e primeiro ano de mandato, é importante considerar que também foi nesse período que a crise financeira passou a impactar a arrecadação dos municípios. Em 2019, as expectativas de retomada da arrecadação melhoraram, fazendo com que se estimassem valores alocados menores na reserva de contingência. Os municípios com posturas "realistas" e adequadas em relação ao manejo das reservas, como medida de gestão de riscos das contas públicas, também têm alcançado melhores resultados fiscais. A literatura que aborda a relevância do realismo orçamentário descreve que as taxas de acerto do planejamento se comportam de acordo com a capacidade de antecipar informações sobre eventos futuros (AQUINO; AZEVEDo, 2015). 
Na Figura 2, é possível identificar em quais períodos dos ciclos políticoorçamentários o comportamento da taxa de reserva de contingência dos grupos eleitorais difere do comportamento fiscal adequado expresso pelo grupo de municípios com superávit (Figura 1). Dessa forma, é possível afirmar com segurança estatística que todo comportamento no cenário eleitoral diferente do comportamento do grupo de municípios com superávit pode evidenciar algum "oportunismo" distributivo por parte dos grupos de candidatos à reeleição.

Figura 2 | Diferenças das médias da reserva de contingência entre os grupos do resultado eleitoral

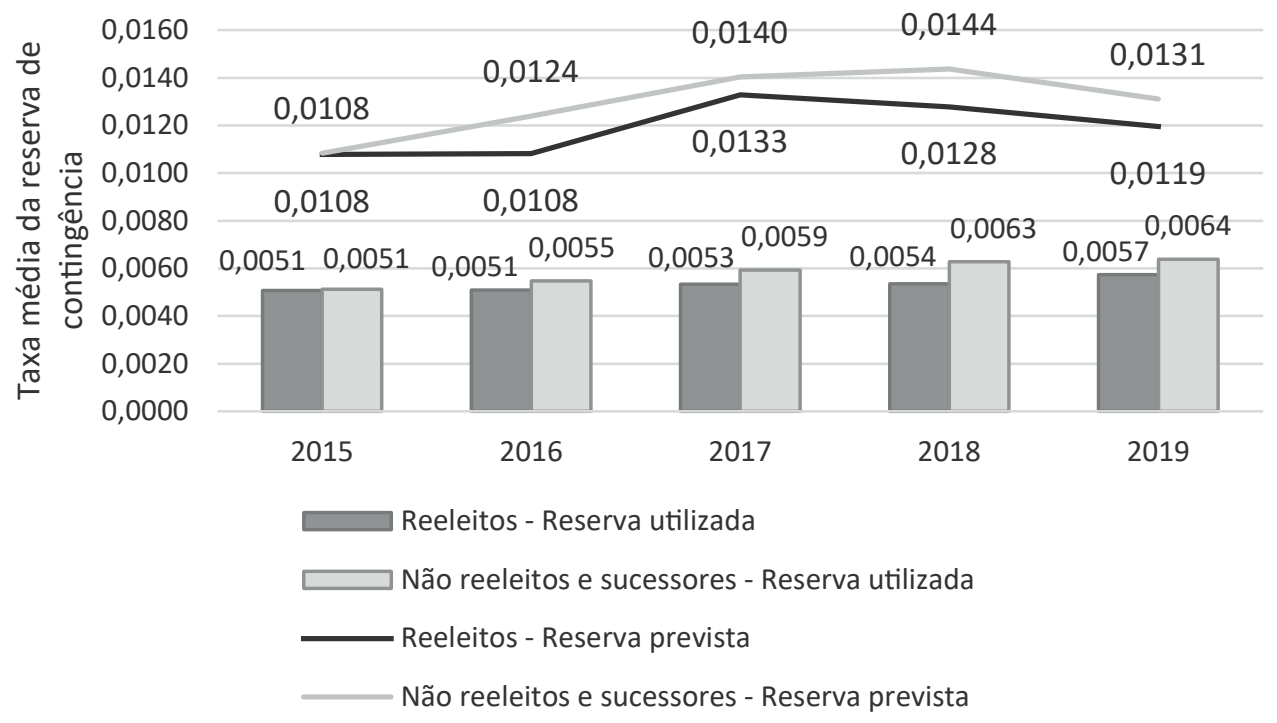

Fonte: elaborado pelos autores.

Nota: (1) Reserva prevista representa as taxas médias de utilização (recursos orçamentários executados) da reserva de contingência para cada um dos grupos do resultado eleitoral; (2) Reserva utilizada representa as taxas médias estimadas (valores do orçamento inicialmente proposto) da reserva de contingência para cada um dos grupos do resultado eleitoral.

O comportamento das taxas médias da reserva de contingência no cenário eleitoral (Figura 2) indica que o grupo de candidatos reeleitos não realizou manobra com a reserva de contingência no período pré-eleitoral, diferentemente do grupo de candidatos não reeleitos, no qual se verificou aumento das taxas médias de reserva de contingência já no período pré-eleitoral, sugerindo algum tipo de oportunismo distributivo, na medida em que não há razões aparentes para tal comportamento de aumento da reserva de contingência para o planejamento orçamentário do ano eleitoral de 2016. Esse cenário 
permite confirmar a hipótese de uso oportunista em períodos pré-eleitorais, haja vista as características dos arranjos políticos, as barganhas e os conflitos distributivos que podem estar envolvidos nessa fase dos ciclos político-orçamentários (SAKURAI, 2009; NAKAGUMA; BENDER, 2010).

\section{Conclusões}

O presente estudo buscou verificar a adequação da reserva de contingência no orçamento dos municípios brasileiros. Apesar de não indicar relação de causalidade, as análises estatísticas possibilitaram confirmar a hipótese de que ocorre tanto comportamento fiscal quanto oportunismo distributivo da reserva no orçamento anual dos municípios, considerando-se a significância estatística apresentada pelos testes de diferenças de médias e os respectivos gráficos sobre cada período analisado.

Foi possível identificar que os municípios com resultado fiscal positivo alteraram o comportamento médio das taxas de reserva na mesma proporção do comportamento do resultado fiscal do período, demonstrando maior sensibilidade ao cenário econômico. Já os municípios com resultado negativo possuem tendência incremental durante todo o período analisado, utilizando-se de pequenos acréscimos nas taxas sem relação com os riscos apresentados pelo cenário fiscal. No cenário eleitoral, os candidatos reeleitos apresentaram comportamento menos oportunista do que os não reeleitos frente ao período pré-eleitoral.

A literatura mobilizada possibilitou entender que a utilização incremental do mecanismo da reserva de contingência - por parte dos municípios deficitários - pode ser decorrente de escolhas políticas e falta de "realismo" desse grupo de municípios. Outra decorrência discutida neste artigo está relacionada com a falta de especificações das bases de cálculos da reserva de contingência na reforma ocorrida no início dos anos 2000 no Brasil (LRF), o que torna possível o desvirtuamento e o oportunismo político em detrimento do cumprimento dos objetivos fiscais. Não se tem previsão de mudanças desse impasse no Projeto de Lei Complementar nㅇ 295/2016, que busca reestruturar as finanças públicas brasileiras. Também não se têm especificações dos procedimentos no 
Manual de Contabilidade Aplicada ao Setor Público (STN, 2019), o qual seria propício para implementar as referidas especificações.

As descobertas contribuem para os estudos de PFM e PBC no campo da administração pública, pois indicam as dicotomias relacionadas às contingências do orçamento anual no cenário dos governos municipais brasileiros. Os resultados, em conjunto com a literatura mobilizada neste estudo, trazem implicações para as dicotomias entre reequilíbrio fiscal e processo político. Os objetivos dos mecanismos orçamentários contingenciais e vinculantes requerem maior especificação das bases de cálculo por parte da legislação para adequação e credibilidade das escolhas adotadas no ciclo PFM.

A pesquisa, ainda, permite evidenciar que as avaliações com as métricas do Banco Mundial não são suficientes para atestar adoção da reserva de contingência como instrumento de gestão de riscos em governos. Nesse ponto, a literatura reforça que o orçamento pode conter teor incremental e ser efetivado de forma cerimonial pelos atores políticos no processo decisório das políticas públicas. Assim, a aplicação real da reserva de contingência pode não estar ligada às estimativas de perdas com eventos fiscais imprevistos, mas carregada por oportunismos distributivos nos ciclos político-orçamentários.

Contudo, este estudo limita-se à análise exploratória dos dados relacionados à adequação das contingências fiscais no orçamento anual, com inferências sustentadas na literatura mobilizada. Apesar de possibilitar o início de uma discussão que implica a necessidade de maiores especificações das bases de cálculo do orçamento anual, não foram apresentados impactos e causalidades na totalidade do orçamento público; exploraram-se apenas as despesas relacionadas ao mecanismo da reserva de contingência. Logo, sugerese que pesquisas futuras investiguem as influências políticas e o impacto fiscal em torno da discricionariedade das bases de cálculo dos mecanismos que compõem o orçamento anual brasileiro, considerando-se as dicotomias apresentadas nesta pesquisa. 


\section{Referências}

Alesina, A.; RoubinI, N. Political Cycles in OECD Economies. Review of Economic Studies, v. 59, p. 663-688, 1992.

Allen, R.; Hemming, R.; Potter, B. H. The International Handbook of Public Financial Management. Hampshire/UK: Palgrave Macmillam, 2013.

ANDREWS, M. What would an ideal public finance management system look like? In: SHAH, A. Budgeting and budgetary institutions. Washington: The World Bank, 2007.

ANESSI-PESSINA, E.; SICILIA, M.; STECCOLINI, I. Budgeting and rebudgeting in local government: siamese twins? Public Administration Review, v. 72, n. 6, p. 875-884, 2012.

ANESSI-PESSINA, E.; SICILIA, M.; STECCOLINI, I. Rebudgeting: scope, triggers, players. Budgetary Research Review, v. 5, n. 1, p. 15-29, 2013.

ANTUNES, M. C. Informações sobre desempenho orçamentário: estudo comparativo das normas orçamentárias no Brasil e Estados Unidos da América. Revista do Serviço Público, v. 70, n. 2, p. 219-238, 2019.

Aquino, A. C. B.; AzeVEdo, R. R. O "ir"realismo orçamentário nos municípios brasileiros. Business and Management Review, v. 5, n. 1, p. 210-224, 2015.

Aquino, A. C. B.; Azevedo, R. R. Restos a pagar e a perda da credibilidade orçamentária. Revista de Administração Pública, Rio de Janeiro, v. 51, n. 4, p. 580-595, 2017.

Azevedo, R. R.; Aquino, A. C. B.; Lino, A. F.; Cavalmoretti, G. A precariedade do conteúdo informacional dos anexos de riscos fiscais de municípios brasileiros. Advances in Scientific and Applied Accounting, v. 12, n. 2, p. 4-22, 2019.

BAnco Mundial. Public Expenditure and Financial Accountability (PEFA) - Framework for assessing public financial management. 2018. Disponível em: https://www.pefa.org/sites/default/files/ PEFA_2016_Framework_Final_WEB_0.pdf. Acesso em: 29 jan. 2020.

BALDISSERA, J. F.; COSTA, R. F. S.; DALL'ASTA, D.; FIIRST, C. Influência das características políticas e eleitorais sobre a abertura de créditos adicionais. Revista Contabilidade, Gestão e Governança, Brasília, v. 22, n. 1, p. 101-117, jan./abr. 2019.

BARTOluzzıo, A. I. S. S.; Dos Anjos, L. C. M. Ciclos políticos e gestão fiscal nos municípios brasileiros. Revista de Administração Contemporânea, v. 24, n. 2, p. 167-180, 2020.

BRASIL, Lei Complementar no 101, de 4 de maio de 2000. Estabelece normas de finanças públicas voltadas para a responsabilidade na gestão fiscal e dá outras providências. Diário Oficial, Brasília, DF, 05 mai. 2000.

BRASIL, Lei no 4.320, de 17 de março de 1964. Estatui Normas Gerais de Direito Financeiro para elaboração e controle dos orçamentos e balanços da União, dos Estados, dos Municípios e do Distrito Federal. Diário Oficial, Brasília, DF, 23 mar. 1964. 
BRASIL. Projeto de Lei Complementar no 295 de 21 de junho de 2016. Estabelece, com amparo nos arts. 163 e 165, § 9o, da Constituição Federal, normas gerais sobre planejamento, orçamento, fundos, contabilidade, controle e avaliação na administração pública; altera a Lei Complementar no 101, de 4 de maio de 2000; e revoga a Lei no 4.320, de 17 de março de 1964. Disponível em: https://www.camara.leg.br. Acesso em: 02 dez. 2019.

BRENDER, A.; DRAZEN, A. How do budget deficits and economic growth affect reelection prospects? Evidence from a large panel of countries. The American Economic Review, v. 98, n. 5, p. 2203-2220, 2008.

CAIDEN, N. The myth of the annual budget. Public Administration Review, v. 42, n. 06, p. 516-523, nov./dec. 1982

CEBOTARI, A. et al. Fiscal risks: sources, disclosure, and management. Washington, DC: International Monetary Fund, 2008.

Conselho Federal de Contabilidade (CFC). Norma brasileira de contabilidade, NBC TSP 03, de 21 de outubro de 2016.

CRUVINEL, D. P.; LIMA, D. V. Adoção do regime de competência no setor público brasileiro sob a perspectiva das normas brasileiras e internacionais de contabilidade. Revista de Educação e Pesquisa em Contabilidade, v. 5, n. 3, p. 69-85, 2011.

Domingos, F. D.; Aquino, A. C. B. Competências (não exercidas) das comissões de orçamento e finanças nas câmaras municipais. Revista de Administração Pública, v. 53, n. 6, p. 1161-1178, 2019.

Downs, A. An economic theory of political action in a democracy. Journal of Political Economy, v. 65, n. 2, p. 135-150, 1957.

FRANCESCO, M. Di. Rules and flexibility in public budgeting: the case of budget modernisation in Australia. Australian Journal of Public Administration, v. 75, n. 2, p. 236-248, 2016.

Gıacomoni, J. Orçamento Público. São Paulo: Atlas, 2010.

LINDBLOM, C. E. The science of "muddling through". Public administration review, v. 12, n. 1, p. 79-88, 1959.

MARCINIUK, F. L.; BUGARIN, M. S. A Influência da reeleição nas políticas fiscais subnacionais. Revista Brasileira de Economia, v. 73, n. 2, p. 181-212, 2019.

Martins, G. A.; TheóPhILo, C. R. Metodologia da investigação científica para Ciências Sociais Aplicadas. São Paulo: Atlas, 2009.

MONTEIRO, B. R. P.; GoMES, R. C. Experiências internacionais com o orçamento público por regime de competência. Revista Contabilidade \& Finanças, São Paulo, v. 24, n. 62, p. 103-112, 2013.

NAKAgUma, M. Y.; BENDER, S. Ciclos políticos e resultados eleitorais: um estudo sobre o comportamento do eleitor brasileiro. Revista Brasileira de Economia, v. 64, n. 1, p. 3-24, 2010.

Nordhaus, W. D. The political business cycle. Review of Economic Studies, v. 42, n. 2, p. 169-190, 1975. 
OliveIRA, F. G. A reserva de contingência inserta no projeto de lei orçamentária anual. Revista Jurídica Luso Brasileira, Lisboa, v. 3, n. 1, 2015.

Peters, B. G. Governance responses to the fiscal crisis - comparative perspectives. Public Money \& Management, v. 31, n. 1, p. 75-80, 2011.

Peters, B. G.; Pierre, J.; RAndma-LiIV, T. Global financial crisis, public administration and governance: do new problems require new solutions? Public Organiz. Rev., v. 11, n. 13, 2010.

PoluITT, C. Public Management reform: reliable knowledge and international experience. OECD Journal on Budgeting, v. 3, n. 3, p. 121-136, 2003.

QueIRoz, D. B.; MoraIS, L. M. F.; SouZA, A. G. S. F.; SILVA, V. K. R. Mandatos eleitorais e ciclos político-orçamentários: evidências dos estados brasileiros. Administração Pública e Gestão Social, v. 11, n. 2, 2019.

ReZENDE, F.; CUNHA, A. A reforma esquecida: orçamento, gestão pública e desenvolvimento. Rio de Janeiro: FGV, 2013.

ROBINSON, M. Aggregate expenditure ceilings and allocative flexibility. OECD Journal on Budgeting, v. 12, n. 3, p. 1-19, 2013.

Rocha, D. G.; MARCElino, G. F.; SANTANA, C. M. Orçamento público no Brasil: a utilização do crédito extraordinário como mecanismo de adequação da execução orçamentária brasileira. Revista de Administração, São Paulo, v. 48, n. 4, p. 813-827, 2013.

Rogoff, K. Equilibrium political budget cycles. The American Economic Review, v. 80, n. 1, p. 2126, 1990.

ROSE, S. Do fiscal rules dampen the political business cycle? Public Choice, v. 128, p. 407- 431, 2006.

SAKURAI, S. N. Ciclos políticos nas funções orçamentárias dos municípios brasileiros: uma análise para o período 1990 - 2005 via dados em painel. Estudos Econômicos, v. 39, n. 1, p. 39-58, 2009.

SCHICK, A. Incremental budgeting in a decremental Age. Policy Sciences, v. 16, n. 1, 1983.

SCHICK, A. The role of fiscal rules in budgeting. OECD Journal on Budgeting, v. 03, n. 03, 2003.

SCHICK, A. Performance budgeting and accrual budgeting: decision rules or analytic tools? OECD Journal on Budgeting, v. 7, n. 2, 2007.

SCHICK, A. The metamorphoses of performance budgeting. OECD Journal on Budgeting, v. 13, n. 2, p. 1-32, 2014.

SECRETARIA Do TESOURo NACIONAL (STN). Manual de contabilidade aplicada ao setor público. 8a edição. Brasília: STN, 2019.

SeCretaria do Tesouro Nacional (STN). Sistema de Informações Contábeis e Fiscais do Setor Público Brasileiro (SICONFI). Disponível em: https://siconfi.tesouro.gov.br/siconfi/pages/public/ consulta_finbra/finbra_list.jsf;jsessionid=ku+3I1NRZKMONKTds4+Moadj.node1. Acesso em: 09 nov. 2020. 
Tribunal Superior Eleitoral (TSE). Repositório de dados eleitorais. Disponível em: http://www. tse.jus.br/eleicoes/estatisticas/repositorio-de-dados-eleitorais-1/repositorio-de-dados-eleitorais. Acesso em: 30 jan. 2019.

Wehner, J. Effective financial scrutiny. In: StAPEnhurst, R.; Johnston, N.; Pelizzo, R. The Role of Parliaments in Curbing Corruption. World Bank Publications, 2006.

WIDYANINGRUM, W.; SETIAWAN, D.; BRAHMANA, R. K. Factors affecting rebudgeting in local government: from organizational feature to political variables. International Journal of Economics and Management, v. 13, n. 1, p. 139-152, 2019.

WILDAVSKY, A. Political implications of budgetary reform. Public Administration Review, v. 21, n. 04, p. 183-190, 1961.

WILDAVSKY, A. The politics of the budgetary process. Boston: Little Brown, 1964.

\section{Lucas Costa Souza}

(D) https://orcid.org/0000-0002-0677-8927

Mestrando em Gestão de Políticas Públicas pela Escola de Artes, Ciências e Humanidades da USP. Bacharel em Ciências Contábeis pela Pontifícia Universidade Católica de São Paulo.

E-mail: lucas.costasouza@usp.br

\section{Ricardo Rocha de Azevedo}

(D) https://orcid.org/0000-0001-6302-0760

Professor do Programa de Pós-Graduação em Ciências Contábeis da Universidade Federal de Uberlândia (PPGCC FACIC/UFU). Doutor e mestre em Controladoria e Contabilidade pela FEARP-USP.

E-mail: ricardo.azevedo@ufu.br

\section{Jaime Crozatti}

(iD) https://orcid.org/0000-0002-3789-8761

Professor do mestrado e da graduação em Gestão de Políticas Públicas da Escola de Artes, Ciências e Humanidades da USP. Doutor em Controladoria e Contabilidade pela FEA/USP.

E-mail: jcrozatti@usp.br 